\title{
A EMERGÊNCIA DA IDEIA DE "AMÉRICA LATINA" NO PENSAMENTO CINEMATOGRÁFICO BRASILEIRO*
}

\author{
Alexandro Dantas Trindade
}

Ao explorarmos, em perspectiva ampla, as diversas representações sobre a formação nacional desde o século XIX, pouquíssimos foram os intelectuais, políticos e letrados brasileiros que conceberam o país de forma articulada ao conjunto dos países de língua espanhola das Américas. Ou seja, até meados da década de 1950, a ideia de inserção do Brasil na "América Latina" nunca fora uma preocupação séria para os intelectuais brasileiros ou, quando muito, era pensada de forma problemática, sob valoração negativa e intencionalidade identitária contrastiva em relação aos demais países do continente.

\footnotetext{
* Este artigo, apresentado no VI Congresso Latinoamericano de Ciência Política (ocorrido em Quito, Equador, em junho de 2012), organizado pela Asociación Latinoamericana de Ciencia Política (Alacip), é parte de uma pesquisa em andamento, com o objetivo de mapear trajetórias de intelectuais ligados ao cinema, compreender a circulação de ideias no âmbito do pensamento social brasileiro e seus efeitos sobre a construção de imagens sobre o Brasil. Em estudos anteriores, analisei parte do diálogo entre referências documentais, pictóricas e imagéticas sobre a identidade nacional em filmes de Humberto Mauro e Nelson Pereira dos Santos (cf. Trindade, 2010) e a circulação do pensamento sociológico das décadas de 1950 e 1960 entre cineastas e críticos de cinema (cf. Trindade, 2011).
} 
Assim, pretendo analisar, de forma preliminar, a emergência de algumas representações sobre "América Latina" entre os intelectuais que, nas décadas de 1950 e 1960, pensaram o Brasil justamente a partir de uma identidade "latino-americana". Meu interesse reside, no plano teórico-metodológico, em investigar o processo de circulação de ideias entre "campos" intelectuais e espaços de produção discursiva distintos, no caso, as relações entre pensamento social e pensamento cinematográfico. Como me proponho a investigar a circulação daquelas ideias, pressuponho também que as fronteiras entre o mundo acadêmico, político e artístico no contexto assinalado eram por demais fluidas, havendo mesmo um embaralhamento entre vocações artísticas, acadêmicas e políticas, sendo o cinema para aquelas gerações "o melhor veículo para refletir sobre e intervir na realidade brasileira” (Ridenti, 2000, p. 93). Daquele diálogo nasceu um conjunto de representações 106 que focaram o Brasil num contexto "latino-americano", explorando-o a partir de conceitos como "subdesenvolvimento", "terceiro-mundismo" ou "dependência" que se traduziram, no caso do cinema e da crítica cinematográfica, em roteiros documentais e ficcionais, imagens da realidade, visões utópicas e distópicas. Nesse sentido, estabelecer as correspondências, ou pontes imaginárias, entre reflexões do pensamento social, alçadas a poderosas imagens sobre a sociedade, e as visões traduzidas em imagens em movimento nas telas, representa para mim o desafio a que me proponho aqui esboçar.

Para melhor compreender o caráter intermitente da reflexão "latino-americana" no pensamento social brasileiro, julgo necessário retomar, ainda que brevemente, uma discussão acerca da controvérsia a respeito da construção da ideia de "América Latina" ao longo dos séculos XIX e XX. Não é minha intenção analisar esse processo em seus pormenores, mas explorar alguns dos sentidos pelos 
quais os intelectuais se pronunciaram em relação à ideia de "América latina" no passado, como contraponto à sua reformulação contemporânea entre os anos 1950 e 1960 em nosso país.

As trajetórias distintas do Brasil e do conjunto dos países do continente, particularmente quanto aos respectivos processos de descolonização e de independência nacional (cf. Peres Costa, 1996; Prado Jr., 1961; Novais, 1995; Carvalho, 1996; Silva Dias, 1986, entre outros), sem dúvida influenciaram os debates intelectuais em torno da formação do Estado e da nação entre as respectivas elites políticas e intelectuais, a começar pela própria gênese da ideia de uma identidade "latino-americana" entre os países de língua espanhola.

A polêmica em torno da construção do conceito de "América Latina" na historiografia contemporânea remonta ao ensaio de 1968, de John Leddy Phelan, "Pan-latinism, French intervention in México (1861-1867) and the genesis of the idea of Latin America"1, para quem a expressão "América Latina" teria sido utilizada pelos intelectuais franceses na década de 1860 como justificativa ideológica ao imperialismo francês no México: para aqueles intelectuais, liderados por Michel Chevalier (1806-1879), haveria uma "afinidade cultural e linguística, uma unidade entre os povos 'latinos', e a França seria sua inspiração e líder natural" em detrimento da influência e dominação anglo-saxãs (cf. Bethel, 2009, p. 290).

Contudo, para autores como Bethel (2009), Bruit (2000) e Farret e Pinto (2011), a expressão tivera sua gênese em anos anteriores àquele contexto, sendo cunhada por escritores e intelectuais hispano-americanos residentes em Paris e Madri. Já em 1856, o conceito estivera ligado a pelo

\footnotetext{
${ }^{1}$ Publicado em Conciencia y autenticidad históricas. Escritos en homenaje a Edmundo O'Gorman (México: Unam).
} 
menos três intelectuais que se pronunciaram originalmente acerca da identidade latino-americana: o jornalista, crítico e poeta colombiano José Maria Torres Caicedo (1830-1889), que mencionou a "pátria más grande - La América Latina”, invocando o legado de San Martín; o intelectual socialista chileno Francisco Bilbao (1823-1865), que organizou o Movimento Social de los Pueblos de La América Meridional, em Bruxelas, e o jurista, político, sociólogo e diplomata colombo-panamenho Justo Arosemena (1817-1896), que se referiu à "América Latina" e ao "interés latino-americano" em Bogotá, além de vários outros intelectuais em anos posteriores (Bethel, 2009, pp. 290-92).

A despeito da fragmentação política da América espanhola em dez repúblicas no momento de sua independência, políticos, escritores e intelectuais, entre 1850 e 1860, advogavam a ideia, anteriormente propagada por Simón Bolívar, Andrés Bello e San Martín, de uma "consciência e 108 identidade hispano-americana/latino-americana comum”, que viria a superar não apenas os nacionalismos locais e regionais, como também se contrapor à “outra” América representada pelos Estados Unidos (Bethel, 2009, p. 292). Em que pese a imprecisão quanto aos critérios utilizados em sua confecção - figurando desde origens étnicas e culturais até consciência política -, e da diversidade de sentido político com a qual foi empregada - na maioria das vezes, excluindo-se tanto as populações ameríndias pré-colombianas como escravos africanos (Farret e Pinto, 2011, p. 31) -, é possível dizer que a ideia de América Latina entre as elites político-econômicas criollas já nascia não apenas imbuída do "anti-imperialismo"² e do esforço identitário, como

\footnotetext{
2 O sentido desse "anti-imperialismo" remonta tanto ao temor da expansão territorial e influência política dos Estados Unidos - representado pela anexação do Texas em 1845, pela Guerra Mexicana de 1846-1848, pela corrida do ouro californiano em 1848, pelo interesse norte-americano na construção do canal do Panamá, pelas constantes interferências em Cuba e Nicarágua -, como também
} 
também, sintomaticamente, da ausência do Brasil (Bethel, 2009, p. 293).

A contrapartida dos intelectuais brasileiros, por sua vez, enfatizava a ideia de que as diferenças geográficas, históricas, econômicas e linguísticas distanciavam o Brasil das experiências sociopolíticas dos demais países do continente. Com o processo de construção estatal e consolidação monárquica a partir do Segundo Reinado, essa singularidade era, ademais, valorizada como signo de estabilidade e "civilização" em comparação com a "barbárie" representada pelas repúblicas hispano-americanas, vistas como violentas e instáveis politicamente, acometidas por insurreições e ditaduras regidas por caudilhos (Bethel, 2009, p. 293; Peres Costa, 1996). No âmbito político, os gabinetes brasileiros do Segundo Reinado não só não se identificavam com a América espanhola, Hispanoamérica ou "América Latina", como também pouco intervinham nos projetos dos países vizinhos, com exceção da região do Rio da Prata, cuja condição de única fronteira "viva" até então entre o Império brasileiro e países hispânicos a investira de interesse estratégico nos planos diplomático e militar - e cujo desenlace trágico foi, sem dúvida, a Guerra do Paraguai entre 1865 e 1870.

No âmbito do pensamento social, a única aproximação se deu com o romantismo brasileiro, mais precisamente com o "indianismo", e mesmo assim a valorização da herança indígena ocorrera num plano idealizado que imaginava o conjunto da América, inclusive os Estados Unidos. Esse quadro de referências permanecerá inalterado até 1870, quando o Manifesto Republicano vem a público defendendo maior aproximação do Brasil com as repúblicas hispano-americanas, e se intensifica, na esfera política, com a Proclamação

em contraposição ao caráter conservador, antiliberal, antirrepublicano e católico representado pela "latinidad" formulada pelos políticos e intelectuais franceses e espanhóis (Bethel, 2009, p. 292). 
da República (1889), quando o Brasil começa a desenvolver relações mais próximas com alguns países vizinhos, como Argentina e Chile (Bethel, 2009, pp. 295-97). Todavia, tanto política como intelectualmente, o contexto da Primeira República foi marcado muito mais pela ideia de "pan-americanismo" - do qual figuram como representantes políticos e intelectuais tais como Joaquim Nabuco (1849-1910) e o Barão do Rio Branco (1845-1912) -, e que tinha como pressuposto o estreitamento de relações com os Estados Unidos como sendo a melhor defesa contra o imperialismo europeu e a garantia de paz e estabilidade na América espanhola (Bethel, 2009, p. 298). Nesse sentido, também aqui o pensamento social brasileiro mostrou-se não apenas distante da aversão e da hostilidade com que muitos intelectuais hispano-americanos, particularmente entre 1880 e a Segunda Guerra Mundial, nutriam em relação aos Estados Unidos e ao pan-americanismo (Bethel, 2009, p. 299), como tam110 bém formulou visões negativas a respeito da América espanhola em obras como as de Eduardo Prado (1860-1901), Oliveira Lima (1867-1928), Joaquim Nabuco e Euclides da Cunha (1866-1909), entre outros.

Contudo, se há certa gravitação entre os intelectuais brasileiros quanto ao empenho em formular interpretações acerca da própria identidade nacional, algumas das mais longevas interpretações problematizaram as "heranças" estrangeiras, esses intelectuais estabeleceram comparações e procuraram situar o Brasil para além de seu território. O ponto que quero enfatizar é que, se não houve até meados da década de 1950 uma reflexão mais sistemática quanto à inserção do Brasil na "América Latina”, houve, entretanto, reflexões que buscaram alargar esse escopo identitário, particularmente à luz da ideia de "iberismo", em seus diversos sentidos, particularmente ao longo das décadas de 1920 e 1930, em que pesem as polêmicas envolvendo os sentidos da modernização para autores como 
Manoel Bomfim (1868-1932), Gilberto Freyre (1900-1988), Sérgio Buarque de Hollanda (1902-1982), Raymundo Faoro (1925-2003) ${ }^{3}$.

\section{Entre a perspectiva da modernização e o espectro do subdesenvolvimento}

Se, até a década de 1930, o pensamento social brasileiro interessara-se mais pela busca de uma identidade nacional ou, em termos mais amplos, circunscrevera tal identidade ao escopo do "pan-americanismo" ou do "iberismo", a inserção do Brasil na "América Latina” passa a ser uma preocupação no final dos anos 1940 e início dos 1950. Palavras como "subdesenvolvimento", "Terceiro Mundo", "imperialismo", "revolução”, "América Latina” começariam a integrar o vocabulário corrente do pensamento social.

Todavia, essa "descoberta" da "América Latina” pelo pensamento brasileiro fora possível também graças ao empenho dos Estados Unidos em estabelecer sua hegemonia no continente após a Segunda Guerra Mundial. Segundo Leslie Bethel (2009), as diferenças entre o Brasil e a América espanhola eram, inclusive, secundárias para os norte-americanos, para quem a influência das potências

\footnotetext{
3 Sinteticamente, podemos entender o "iberismo" como a valorização ou a recuperação das "raízes ibéricas" da nacionalidade brasileira, caminho trilhado por autores desconfiados de que a modernização das relações sociais, o liberalismo político, ou o princípio da representação política ou mesmo da democracia pudessem ser adotados no Brasil, uma vez que essas instituições não corresponderiam à realidade das nossas tradições e costumes políticos. O "iberismo" pressupunha a ideia de que Portugal e Espanha não teriam partilhado valores tipicamente modernos, como individualismo, contrato, mercado, competição, conflito e democracia. Suas tradições políticas teriam, antes, gravitado em torno de valores tais como contemporização, integração, predomínio de interesses coletivos e comunitários sobre os individuais, personalismo, patriarcalismo etc. Pode-se dizer que o "iberismo" é uma tradição alternativa ao "Ocidente" anglo-saxão, puritano, calcado numa ética do trabalho de matriz protestante. Entre o final do século XIX e o início do XX, intelectuais como Manuel Bomfim, Gilberto Freyre, Sérgio Buarque de Holanda e Raymundo Faoro, entre outros, posicionaram-se de distintas maneiras em relação à ideia de "iberismo", com resultados analíticos, teóricos e políticos igualmente diversos (cf. Carvalho, 1991; Ricupero, 2008; Bastos, 2006).
} 
nazifascistas europeias e, posteriormente, a ameaça da expansão comunista no continente eram os principais temores. Foi estabelecido, então, um conjunto de ações voltadas para o estreitamento de laços continentais, com a criação de agências como a Occia (Office of the Coordinator of Inter-American Affairs, em 1941, coordenada por Nelson Rockfeller); a Cepal (Comissão Econômica para a América Latina, das Nações Unidas, em 1948); os diversos "Latin American Studies" instituídos em universidades; a promoção de conferências como a Interamericana para a Manutenção da Paz e da Segurança no Continente (Rio de Janeiro, 1947) e da Internacional Americana (Bogotá, 1948), quando, respectivamente, foi assinado o Tratado Interamericano de Assistência Recíproca e estabelecida a Organização dos Estados Americanos (OEA), visando dar moldura institucional às relações interamericanas no pós-guerra. Além desses organismos

112 e acordos multilaterais, vários autores norte-americanos publicaram obras, a partir dos anos 1940, com referências a países latino-americanos, englobando também o Brasil (Bethel, 2009, pp. 307-10).

A par do estreitamento diplomático entre Brasil e Estados Unidos, vivenciado ao longo da Segunda Guerra Mundial, a política externa independente adotada pelo Brasil no segundo governo Vargas em 1951, seguida pelos governos Jânio Quadros em 1961 e João Goulart em 1961-1964 reforçou a identidade "latino-americana", em particular ao firmar relações com Cuba após sua revolução e com os países do "Terceiro Mundo" subdesenvolvido (Bethel, 2009, p. 311), culminando com as análises formuladas pela Cepal e a repercussão da "teoria da dependência": cientistas sociais como Fernando Henrique Cardoso, Ruy Mauro Marini, Theotonio dos Santos, Celso Furtado e Darcy Ribeiro protagonizaram os principais lances desse "latino-americanismo", tanto pela difusão de suas ideias como, tragicamente, pela 
experiência de vários deles no exílio em países do continente após o golpe militar de $1964^{4}$.

Em meados da década de 1940, tanto a recepção desse conjunto de ações como a circulação de ideias a respeito da inserção internacional do Brasil ocorreram simultaneamente ao processo de modernização econômica e social do país. No contexto de redemocratização após a ditadura do Estado Novo (1937-1945), e ao longo das décadas seguintes, o Brasil vivenciaria um período de intensas transformações no campo da economia, da política, da cultura, sem contar o próprio dinamismo da estrutura social. A reflexão em torno daquelas mudanças foi elemento fundamental, não apenas para a constituição das ciências sociais, como também compartilhada em diversas esferas e campos de atuação, e palavras como as mencionadas anteriormente (relembrando: "subdesenvolvimento", "Terceiro Mundo”, "imperialismo”, "revolução”, “América Latina”) buscavam traduzir, ainda que parcialmente, as vicissitudes históricas pelas quais passavam aquelas gerações.

A rapidez com que fenômenos como a urbanização e a industrialização se fizeram sentir, sobretudo nos anos de 1950, foi de tal magnitude que imprimiu no horizonte de expectativas a imagem de uma sociedade em movimento, imagem esta que teria, segundo André Botelho (2008, p. 15), encontrado na intelligentsia, composta por artistas, cientistas e escritores, seus mais empenhados portadores sociais. Mais do que simplesmente registrar a intensidade das mudanças em curso, aquela imagem, ao acentuar a distância entre o presente e as expectativas de futuro, teria conferido "sentido à busca de um ideal de moderno marcado pelo progresso, autoaperfeiçoamento ilimitado do mundo social, e pela reorientação de valores, interesses, condutas e instituições" (Botelho, 2008, p. 15).

\footnotetext{
${ }^{4} \mathrm{O}$ escopo deste artigo não permite, contudo, aprofundarmos as diferenças entre as concepções cepalinas, dualistas, terceiro-mundistas e as formulações da "teoria da dependência”.
} 
Embora não totalmente livre da imagem idealizada de harmonia social e da busca pela identidade nacional que caracterizaram o pensamento social brasileiro das décadas de 1920 e 1930 (Ianni, 2004, p. 25), o debate em torno da questão nacional nos anos 1950 passava pela recusa em legitimar formas tradicionais de sociabilidade. Ao contrário, aquele debate vislumbrava a abertura diante de perspectivas mais universalistas e secularizadas, aderia à ordem social competitiva como padrão normativo de uma sociedade democrática e reconhecia a emergência de novos atores sociais (Botelho, 2008, p. 15). Em suma, orientava-se admitindo o conflito como forma de construção da sociedade.

$\mathrm{Na}$ trilha do argumento elaborado acima, pode-se dizer que as distintas concepções de sociedade elaboradas a partir da década de 1950 constituíram-se numa "constelação histórico-intelectual" que "sedimentou um campo problemático e conheceu desenvolvimentos que, em grande 114 medida, se imbricaram com as ações ordinárias do homem comum e consolidaram, ao longo do tempo, modos de pensar o país que se tornaram hegemônicos" (Botelho, 2008, p. 21). Como constelação, as preocupações esboçadas naquele contexto não partilhavam das mesmas premissas, sendo sintomático disso, por exemplo, o debate em torno dos rumos da industrialização, do papel do Estado, da configuração das classes sociais, do significado da apreensão analítica da mudança para o conjunto das ciências sociais, e, de forma não antes vista, da inserção do Brasil nos quadros de uma ideia de "América Latina".

Particularmente no âmbito da imaginação das ciências sociais, que se afirmava como recurso poderoso de interpretação da realidade, o debate travado acerca do significado da mudança social representou clivagens muitas vezes antagônicas quanto às perspectivas de futuro, ainda que partilhassem ao menos de um ponto comum: a correspondência entre "fazer ciência" e "fazer história" (Villas Bôas, 2006, 
p. 65), isto é, a tensão entre o empenho por desvendar as estruturas que constituíam a sociedade e o ímpeto por acelerar as mudanças rumo à modernidade.

No que diz respeito ao pensamento cinematográfico no Brasil, particularmente entre a recepção do neorrealismo italiano e a emergência e reflexão posterior sobre a experiência do Cinema Novo, tampouco houve convergência, mesmo entre cineastas e críticos agrupados em torno das mesmas revistas, círculos intelectuais e suas respectivas coteries. Entretanto, e aqui arriscamos algumas hipóteses de trabalho bastante provisórias, é possível identificar ao menos duas grandes orientações acerca do sentido que deveria ter a representação da sociedade brasileira nas telas, representação esta que, no caso de alguns filmes concebidos no âmbito do Cinema Novo, vislumbrava também uma identidade latino-americana. De um lado, a perspectiva quanto ao desvendamento e a "reapresentação" da sociedade, estabelecendo os parâmetros para um "cinema verdade"; de outro, a aposta numa "representação" social que fizesse jus aos clamores de mudança e se empenhasse enquanto vanguarda da revolução social. Perspectivas estas que, como veremos, não eram necessariamente antagônicas, uma vez que prevalecia em ambas a ênfase no engajamento, embora o debate quanto à forma narrativa e da leitura que se fazia em torno de uma ou outra proposição levassem os cineastas e críticos a se posicionarem quanto às interpretações urdidas pela imaginação social.

Em suma, a questão de como poderia ser traduzida cinematograficamente a ideia de sociedade em movimento não se reduzia à sua dimensão estética, mas inevitavelmente envolvia questões ligadas ao protagonismo político e intelectual daqueles que se imaginavam também, de alguma forma, responsáveis por imprimir e difundir uma consciência sobre a realidade social através do cinema. Nas palavras de Glauber Rocha (1939-1981), um dos mais emblemáticos 
cineastas e teóricos de cinema do período, se "los ingenieros son artistas de la comunicación sobre el abismo, los artistas son ingenieros de un afectivo puente mental" (de Glauber Rocha para Alfredo Guevara, maio de 1971, apud Avellar, 1995, p. 31).

\section{Entre a realidade e o sonho: parâmetros de um debate}

Não sem certo exagero, José Carlos Avellar (1995) situou entre o final da década de 1950 e início da década de 1980 o período em que pela última vez, tanto no Brasil como na América Latina, houve um efetivo pensamento cinematográfico. Definindo como "teoria em transe" os textos de cineastas e críticos empenhados em pensar o cinema entre a "realidade e o sonho, entre a razão e o delírio", Avellar analisou um conjunto de projetos não filmados, isto é, textos que se situavam entre possíveis roteiros de filmes e teorias sobre cinema, expressos em artigos de jornal, presentes

116 em depoimentos e entrevistas, participações em congressos e debates. Cineastas como Glauber Rocha e Geraldo Sarno no Brasil, Tomás Gutiérrez Alea e Julio García Espinosa, ambos de Cuba, Fernando Birri e Fernando Solanas, ambos da Argentina, e Jorge Sanjinés da Bolívia, foram os principais protagonistas de um projeto que visava desenvolver uma nova linguagem cinematográfica, movimentando-se entre uma reapresentação e uma superação da realidade latino-americana. Tais textos, no entendimento de Avellar, podem ser concebidos como sugestões de modelos de dramaturgias cinematográficas que extrapolariam o produto final, isto é, o filme em si mesmo, para se alçarem as perspectivas sobre como pensar a própria realidade subdesenvolvida, dilacerada e descontínua, tanto brasileira como latino-americana.

O subdesenvolvimento é mesmo uma força autodevoradora que dilacera as possibilidades dos indivíduos e paralisa a 
criatividade. O cinema que começamos a fazer na metade dos anos 50 partiu exatamente da descontinuidade, instrumento arrancado de dentro do subdesenvolvimento, para voltar-se contra ela, para transformar em ação o que se impõe como impossibilidade de invenção livre. Os filmes parecem inconclusos. As teorias criadas em torno deles também. Uma coisa e outra têm um idêntico tom de roteiro, primeiro pedaço de uma imagem que está nascendo naquele exato instante, ou esboço imperfeito de uma imagem que só vai nascer adiante (Avellar, 1995, p. 9).

A tensão exposta acima, entre "realidade e o sonho, entre a razão e o delírio", serviu ao autor como indício de posicionamentos de cineastas e críticos de cinema em torno da alternativa entre registrar o fluxo das mudanças, "reapresentando" a realidade a partir da tela, e intervir no processo de forma revolucionária. O primeiro movimento situa-se na segunda metade da década de 1950: o modo de pensar a experiência cinematográfica "recuperava [...] o pedaço de registro objetivo da realidade que existe na fotografia em movimento, e negava o pedaço de imagem livremente inventada, subjetiva, que também faz parte dela" (Avellar, 1995, p. 32). Os jovens cineastas lançavam mão de novos recursos tecnológicos que lhes garantiam agilidade, mobilidade e davam a sensação de que "na ação em continuidade e no espaço em profundidade o expectador podia enfim encontrar no filme uma experiência visual idêntica à que vivia em seu cotidiano" (Avellar, 1995, p. 33). O cinema verdade, de caráter documental, além da difusão do neorrealismo italiano, garantia legitimidade ao empenho em reapresentar a realidade e deslegitimava a montagem, vista como manipulação que "impedia o espectador de agir livremente diante da cena, e afastava o filme de sua essência, a reapresentação do mundo" (Avellar, 1995, p. 33). Em contraponto a essa perspectiva, o segundo movimento: a manipulação, ou 
montagem, acenava para a reflexão, para a subjetividade e abstração, incorporando o engajamento e a ação à denúncia das condições objetivas.

Como afirma Avellar, de um lado o neorrealismo, cujo precursor fora o teórico Cesare Zavattini (1902-1989), na Itália do imediato pós-guerra; de outro, a montagem elaborada advinda da experiência fílmica de Sergei Eisenstein (1898-1948), emblema do cinema soviético e do zhdanovismo, estética do realismo socialista. Glauber Rocha, no início da década de 1960, estava em busca da síntese que pudesse significar uma nova linguagem cinematográfica latino-americana, um invento "a partir de uma fusão do que os olhos europeus viam como propostas antagônicas, Zavattini e Eisenstein. Para facilitar a fusão, o olhar de Buñuel, [...] A receita para a síntese Zavattini/Eisenstein: rasgar o olho ao meio como Buñuel" (Avellar, 1995, p. 34). Para Glauber Rocha, a linguagem de Buñuel seria por excelência a do 118 homem oprimido, pois

[...] no absurdo quadro da realidade do Terceiro Mundo, é a consciência possível: diante da opressão, do policialesco, do obscurantismo e da hipocrisia institucionalizada, ele representa a moral libertária, abertura de caminho, constante processo de rebeldia clarificadora [...]. Esta libertação, contudo, não é uma fuga, mas uma arma que vergasta, como o Cristo de Pasolini, os símbolos da sociedade capitalista subdesenvolvida. O herói de Buñuel é [...], na última redução, um fanático latino organicamente faminto: o comportamento de um faminto é tão absurdo que seu registro real cria o neo-sur-realismo; sua moral, como subproletariado, é mais metafísica do que política (Rocha, 2006, p. 189; grifos do autor).

É nessa síntese que podemos vislumbrar o projeto estético-político de um cinema "latino-americano" proposto 
por Glauber Rocha no bojo do movimento cinemanovista, e que ganha repercussão imediatamente à sua confecção no âmbito da crítica de cinema. A gênese desse projeto estético repousava, contudo, em meados dos anos 1950, nos debates em torno do nacionalismo de esquerda, do engajamento artístico e da busca de um "cinema verdade", argumentos aos quais Glauber e outros cineastas e críticos começariam a se distanciar em meados da década de 1960.

\section{0 cinema em busca da realidade: neorrealismo, PCB e nacionalismo de esquerda}

A emergência de um cinema que buscava tanto retratar fielmente a realidade como criar novas representações de "povo" e "nação" alicerçou-se na confluência de vários movimentos estéticos, políticos e intelectuais; o aspecto ambíguo envolvendo perspectivas identitárias, como o nacionalismo, e emancipadoras, como a perspectiva da revolução social, pode ser interpretado à luz daquilo que Marcelo Ridenti define como o espectro do "romantismo revolucionário": um conjunto de ideias, atitudes, escritos literários, ideais estéticos etc., que primavam por uma utópica vontade de transformação, mas sobretudo com os olhos voltados para o passado. Movia-o a

[...] idealização de um autêntico homem do povo, com raízes rurais, do interior, do "coração do Brasil", supostamente não contaminado pela modernidade urbana capitalista. Como o indígena exaltado no romance Quarup, de Antonio Callado (1967), ou a comunidade negra celebrada no filme Ganga Zumba, de Carlos Diegues (1963), na peça Arena canta Zumbi, de Boal e Guarnieri (1965), entre outros tantos exemplos (Ridenti, 2000, p. 24).

O romantismo revolucionário guarda semelhanças com o conservadorismo, sobretudo na sua crítica ao capitalismo, à 
racionalização e desencantamento do mundo. Nesse sentido, reflexões sobre as raízes "ibéricas", bem como aspectos do próprio pensamento conservador seriam retomados e ressignificados nos anos 1960: longe de serem interpretados como "atraso", eram agora concebidos como projetos utópicos de futuro e de rompimento com o status quo, todavia desconfiando-se das premissas liberais. Ou seja, perfaziam uma forma específica de crítica à modernidade, rumo a um socialismo não conciliador com o "desenvolvimento das forças produtivas".

Segundo Marcos Napolitano (2007), o campo cultural e artístico da esquerda no Brasil foi hegemonizado pelo PCB e seus simpatizantes - sobretudo com o processo de abertura a partir de 1956, condicionado pela política de distensão do Partido Comunista da União Soviética, que, até então, imprimia sobre o PCB a vigilância quanto à doutrina do realismo socialista. Desde então, o PCB construiria uma nova política cultural, "mais aberta a alianças de classe e a 120 formas mais universalistas", a qual visava conjugar a direção ao nacional-popular incorporando a cultura burguesa refinada e erudita, devendo ambas "fundamentar a 'revolução nacional, democrática e anti-imperialista'” (Napolitano, 2007, p. 589). Para Marcelo Ridenti (2008, 2010), a relação entre o Partido e os artistas era, contudo, tensa e ambígua, por haver uma via de mão dupla entre o prestígio que artistas emprestavam ao Partido e a rede de apoio e solidariedade internacional a que muitos destes recorriam, particularmente devido aos riscos de perseguição política no Brasil.

A despeito da imposição doutrinária e do patrulhamento ideológico a que eram submetidos, a partir da "virada cultural" de meados da década de 1950, e com o alinhamento do partido com o nacionalismo de esquerda, cineastas como Nelson Pereira dos Santos e historiadores como Alex Viany, com o beneplácito do Partido, puderam tanto exercer sua experiência cinematográfica como a crítica à luz daquele compromisso em revelar a realidade brasileira. 


\section{O episódio envolvendo o primeiro longa-metragem de Nel-} son Pereira dos Santos, Rio, 40 graus, rodado em 1954, dá uma dimensão daquela ambiguidade: por não aceitar a proposta autônoma do cineasta, o Partido puniu Nelson Pereira com o seu deslocamento para um comitê cultural de menor importância. No entanto, uma vez que o filme fora proibido pelo chefe de polícia do Distrito Federal, o próprio PCB engajou-se na luta pela sua exibição, o que veio a ocorrer em 1955 (Ridenti, 2008, p. 188).

Por outro lado, a difusão do neorrealismo italiano no Brasil $^{5}$, iniciada em 1947 com a exibição de filmes como

\footnotetext{
${ }^{5}$ Segundo Mariarosaria Fabris, entretanto, se é possível estabelecer a origem do neorrealismo italiano com Roma, cidade aberta, de 1945, de Rossellini, o mesmo não se pode afirmar quanto à duração desse ciclo. É que, a rigor, sob a etiqueta "neorrealista", cineastas apresentaram fórmulas estéticas muito díspares entre si, não havendo um "movimento que agrup [asse] sob a mesma bandeira as diferentes manifestações do cinema italiano engajado daqueles anos". Para a autora, o neorrealismo enquanto movimento estético não existiu, sendo muito mais um "tipo de produção que tentou levar o público a refletir sobre as relações entre o homem e a sociedade", havendo assim tantos neorrealismos quantos foram os neorrealistas, tamanha diversidade de expressões que aquela fórmula abrigou (Fabris, 1994, p. 56). Agora, falando em termos cronológicos (1945-1948) e restringindo-se à chamada trindade neorrealista (Rossellini-De Sica/Zavattini-Visconti), o que aqueles filmes fizeram foi transformar o homem e a paisagem em protagonistas, inspirando-se "diretamente na realidade e na necessidade de registrar o presente: a guerra e a luta de Resistência antifascista, num primeiro momento, mas, logo depois, também a 'questão meridional', a reforma agrária, a crise do desemprego e o subemprego nas áreas urbanas, a emigração, o abandono da infância e da velhice, a condição da mulher" (Fabris, 1994, p. 26). Nos filmes que celebravam a guerra e a Resistência, o que mais se exaltava era o espírito de solidariedade que havia animado o povo italiano, e, em nome dessa solidariedade, "camuflavam-se as contradições internas que prenunciavam os conflitos ideológicos que iriam surgir entre os vários partidos políticos após a Libertação" (Fabris, 1994, p. 27), daí o cunho humanista e a conciliação ideológica, por exemplo, entre católicos e comunistas, temática presente nos filmes de Rossellini e Vittorio De Sica. O "mito do pobre como categoria universal", a transferência para o proletariado de tensões e inquietações de pequena burguesia, entre outras questões, foram por sua vez pouco exploradas pela esquerda, que adotou o neorrealismo na falta de um programa cultural alternativo. Por outro lado, os católicos, que contavam com uma vasta organização cultural, elaboravam sua própria estratégia que passava, por exemplo, pelo boicote às melhores produções neorrealistas, tachadas de amorais e filocomunistas (Fabris, 1994, p. 30). Julgo importante ao menos mencionar tais questões aqui, uma vez que o escopo deste artigo não permite o seu aprofundamento.
} 
O bandido, de Alberto Lattuada, e Roma, cidade aberta, de Roberto Rossellini, impactou as elites culturais, demonstrando a viabilidade de realizar filmes com baixo orçamento e distantes das fórmulas estéticas convencionais (Napolitano, 2007). Nesse momento, se veem as primeiras manifestações publicadas em Fundamentos, revista de cultura geral ligada ao PCB e fundada em 1948, e os primeiros Congressos Nacionais de Cinema Brasileiro (1952 e 1953), ambos reivindicando renovação do cinema nacional, tanto do ponto de vista dos temas como da forma estética e narrativa, e também defendendo uma legislação protecionista que garantisse condições de mercado para a indústria cinematográfica no país.

Naquele contexto de meados da década de 1950, ao menos dois intelectuais despontavam como precursores do que viria a ser conhecido como "cinema novo": Paulo Emílio Salles Gomes e Alex Viany. Paulo Emílio, nas críticas 122 publicadas no Suplemento Literário do jornal O Estado de S. Paulo, entre 1956 e 1965, desenvolvia uma reflexão sobre o cinema que se ancorava na busca de uma "originalidade formativa da consciência nacional em meio à precariedade técnica do subdesenvolvimento" (Napolitano, 2007, p. 602), reflexão que seria sintetizada no importante Cinema, trajetória no subdesenvolvimento, publicado em $1973^{6}$.

Quanto ao crítico e cineasta Alex Viany, suas reflexões no período dão bem a medida do debate em torno da recepção do neorrealismo no Brasil e as questões relacionadas ao tipo de realismo que se deveria formular. Membro do PCB desde 1951, e estabelecendo diálogo entre realismo socialista e uma orientação que fugisse aos limites estéticos daquela vertente, Viany reivindicava um cinema que representasse fielmente a realidade nacional, empenhando-se em

\footnotetext{
${ }^{6}$ Os limites e propósitos deste artigo impedem, todavia, uma exposição mais sistemática do pensamento de Paulo Emílio Salles Gomes.
} 
aplicar no Brasil tanto as ideias do italiano Guido Aristarco como de Cesare Zavattini. Assim, também Viany incorria na tensão que Glauber Rocha iria vivenciar anos depois. Ocorre que, segundo Arthur Autran (2002), Guido Aristarco, influenciado pela estética de Georg Lukács e de Antonio Gramsci, imputava ao cinema uma direção, uma narrativa do mundo, entendendo a montagem como elemento fundamental para a linguagem fílmica. Além disso, ao afirmar que a montagem, não sendo específica do cinema, mas encontrada também na literatura, música e teatro, não era o que definia o valor artístico de um filme, uma vez que, sem uma narrativa, uma psicologia, um tema e um conteúdo, este nada diria sobre a realidade, a tarefa do crítico e do ensaísta seria, então, "encontrar as razões profundas que induziram o realizador a empregar este ou aquele método de trabalho, este ou aquele meio expressivo, esta ou aquela estrutura. Tudo isso só é possível se inserirmos o cinema nos problemas da arte, da vida, da história, da cultura" (Aristarco, 1961 apud Autran, 2002, p. 65). Dessa forma, suas ideias se afastariam do modelo proposto por Zavattini, qual seja, o de um confronto direto entre cinema e realidade e uma orientação inata do cinema para a vida, a conquista do real fora de qualquer fórmula preestabelecida, ou, em suma, uma perspectiva naturalista. Segundo Autran, Viany empenhava-se em provar não apenas que a estética subordinava-se à filosofia e à política, como também concebia a obra de arte como "reflexo" da classe, da época e do país aos quais pertencia o artista. O que faria com que recaísse sobre o último, para Viany, a responsabilidade pela fidelidade ao real: sendo engajado politicamente e defendendo abertamente ideias de esquerda ou de direita, seria consciente; ao acreditar fazer arte pura, seria inconsciente (cf. Autran, 2002, p. 65). Todavia, mesmo aquele que se propusesse a uma arte pura, ao se defrontar com temas e questões "populares", tenderia a se tornar consciente, daí a 
possibilidade vislumbrada quanto à assimilação do neorrealismo no Brasil: a partir da temática, dos problemas especificamente nacionais, quando não do envolvimento com um projeto de corte nacionalista.

E foi precisamente sob a bandeira do nacionalismo que muitos intelectuais, a exemplo de Alex Viany, entenderam o significado de "consciência" e "alienação". Com efeito, segundo José Mario Ortiz Ramos, até 1964 o “conceito de alienação se entrecruzava com o nacionalismo, costurando o tecido que sustentava, e de alguma forma unificava, a diversidade da produção cultural da época" (Ortiz Ramos, 1983 apud Ridenti, 2000, p. 93). Parte significativa do léxico do nacionalismo foi capitaneada, nos anos 1950 e 1960, pelo Instituto Superior de Estudos Brasileiros (Iseb) ${ }^{7}$, promotor e difusor do nacional-desenvolvimentismo, ideologia incorporada por parcelas da esquerda política, do campo intelectual, do cenário artístico e do 124 pensamento de cinema. A despeito das divergências entre seus membros quanto ao conteúdo, limites e possibilidades da ideologia nacionalista, o Iseb foi responsável pela elaboração de uma série de conceitos políticos e filosóficos que, ao se difundirem pela sociedade, se constituíram também em categorias de apreensão e compreensão da realidade brasileira empregados por um amplo arco ideológico (Ortiz, 2006, pp. 47-48). De maneira geral, os intelectuais ligados ao Iseb fundamentavam-se em uma perspectiva dualista entre setores tradicionais e modernos da sociedade: os primeiros representados pela classe latifundiária, pela burguesia mercantil, pela classe média não

\footnotetext{
${ }^{7}$ O Iseb foi criado em 1955 pelo governo Café Filho, e era vinculado ao Ministério da Educação e Cultura. Possuía autonomia administrativa e liberdade de pesquisa, opinião e cátedra, destinada ao estudo das ciências sociais e, durante o governo Juscelino Kubitschek (1956-1961), destacou-se como formulador da perspectiva nacional-desenvolvimentista. Foi extinto três dias após o golpe militar de 31 de março de 1964.
} 
produtiva e parcelas do proletariado; ao passo que os setores modernos eram encontrados na burguesia industrial, no proletariado urbano e rural e na classe média produtiva, e tal compartimentação seria determinada pela relação que cada classe tivesse com o processo de industrialização (Toledo, 1978, p. 117). Ou seja, o caráter tradicional ou moderno de cada classe ou segmento social se daria pelo favorecimento ou resistência àquele processo, daí a denúncia que os intelectuais isebianos faziam do fenômeno do "parasitismo social", entendido como "herança colonial" impeditiva da "completa hegemonia dos interesses industriais ou "progressistas"”, bem como a permanência de interesses retrógrados e decadentes que poderiam "contaminar a estrutura das relações sociais" (Toledo, 1978, p. 118).

Pode-se perceber quanto a crítica e a produção cinematográfica incorporaram essa leitura acerca do "atraso" com a repercussão de dois filmes de Glauber Rocha: seu primeiro longa-metragem, Barravento, de 1961, e Deus e o diabo na terra do sol, de 1964. Ambos podem ser lidos por aquela chave interpretativa, embora o primeiro fosse mais explícito quanto à crítica da alienação mística, ao passo que o segundo visava a uma ruptura revolucionária, estética e ideológica, ainda que sob inspiração do léxico do nacional-desenvolvimentismo.

Em Barravento, o letreiro que introduz o filme é contundente:

No litoral da Bahia vivem os negros puxadores de "xaréu", cujos antepassados vieram escravos da África. Permanecem até hoje os cultos aos deuses africanos e todo esse povo é dominado por um misticismo trágico e fatalista. Aceitam a miséria, o analfabetismo e a exploração com a passividade característica daqueles que esperam o reino divino.

"Iemanjá" é a rainha das águas, a "velha mãe de Irecê", 
senhora do mar que ama, guarda e castiga os pescadores. "Barravento" é o momento de violência, quando as coisas da terra e mar se transformam, quando no amor, na vida e no meio social ocorrem súbitas mudanças. Todos os personagens apresentados neste filme não têm relação com pessoas vivas ou mortas e isto será apenas mera coincidência. Os fatos, contudo existem. Barravento foi realizado numa aldeia de pescadores na praia de Buraquinho, alguns quilômetros de Itapoan, Bahia.

Corroborando os letreiros, em Revisão crítica do cinema brasileiro, escrito em 1963, Glauber registrava que desejara fazer um filme de "ruptura formal como objeto de um discurso crítico sobre a miséria dos pescadores negros e sua passividade mística” (Rocha, 2003, p. 160). Alex Viany, em texto escrito em 1962 sobre o filme, valorizava em Glauber justamente a postura "consciente de suas responsabilidades 126 de artista no Brasil da segunda metade do século XX”, a qual ele assumia ao enfrentar e atacar,

[...] como um pequeno Quixote descabelado, o misticismo paralisante de sua vila de pescadores negros, até lá levando uma mensagem de luta, talvez ainda confusa e desarvorada, por intermédio de Firmino, sem dúvida uma das figuras mais complexas e fascinantes em toda a história do cinema brasileiro (Viany, 1999, p. 48).

A despeito de falhas pontuais de roteiro, direção, cinegrafia e sonografia, Viany (1999, p. 49) admitia que o filme cumpria com o "completo e apaixonado entrosamento com os problemas de nossa atualidade", embora o mais grave problema tivesse a ver justamente com a sua deficiente "comunicação": ou seja, como "obra de arte empenhada", o filme deveria ser compreendido principalmente "pelas plateias envolvidas nos mesmos problemas daqueles 
pescadores castrados e enjaulados por sua devoção a Iemanjá" (Viany, 1999, p. 49). Com isso, Viany queria destacar o fato de Barravento não ter tocado o "espectador médio, viciado no tatibitate cinema de fórmula [hollywoodiana]", sobretudo ao não ter definido melhor o "meio social dos pescadores, de suas relações com as forças dominantes do mundo que os cerca" (Viany, 1999, p. 49), problema esse que atormentava de modo geral a crítica de cinema daquele contexto, mas que só viria a ser seriamente refletida no contexto da derrota do projeto nacionalista de esquerda com o golpe militar de 1964.

Já sobre Deus e o diabo na terra do sol, de 1964, Viany teve uma impressão diferente. Em 24 de março de 1964, o crítico e historiador conduziu um debate patrocinado pela Federação dos Clubes de Cinema do Brasil e pelo Grupo de Estudos Cinematográficos da União Metropolitana dos Estudantes, que contou com a presença de Walter Lima Jr., David Neves, Leon Hirszman e do próprio Glauber Rocha, que chegou durante a conversa. Vale à pena transcrever alguns trechos daquele que foi um dos primeiros debates sobre o filme, uma vez que as dificuldades de entendimento eram, para Viany e outros participantes, dadas pelo seu caráter revolucionário, tanto ideológica como cinematograficamente. Ainda para Viany, embora o filme tivesse uma preocupação desmistificadora e cumprisse a função de desmascaramento, e, com isso, uma roupagem realística, ele não era

[...] de maneira alguma um filme realista. É um apólogo, uma alegoria, e como tal deve ser visto. Personagens de alegoria são personagens necessariamente alegóricos, representativos de grupos sociais, de ideias. E, neste filme, então, quando pretende mostrar que Deus e o diabo existem de um lado e de outro, há mesmo uma exigência real de confusão. Isso é proposital no filme. Quase todos os personagens do filme são ambíguos (Viany, 1999, p. 55). 
Ao se pronunciar no debate, Glauber rebatia em parte o caráter alegórico e elíptico do filme, afirmando que a narrativa elíptica era expressão real na vida de Vitória da Conquista, Cocorobó e outras cidades baianas, que ele conhecia profundamente e, portanto, havia se inspirado naquela realidade. Personagens como o enigmático Antônio das Mortes, inspirado no major José Rufino que ainda vivia em Jeremoabo, era um exemplo disso, como também a introdução do cancioneiro popular das feiras nordestinas para narrar a história. Glauber afirmava que

[...] não foi nenhuma escolha minha, só uma observação mais atenta do problema, que a melhor forma de contar uma história do Nordeste é integrar essa história naquela estrutura narrativa, porque toda a realidade do Nordeste é transformada em lenda, em análise da realidade, pelos cegos trovadores e pelas pessoas que relatam os casos

128 (Glauber apud Viany, 1999, p. 60).

Ainda naquele debate, Leon Hirszman enfatizava a necessidade de inserção do filme num contexto histórico mais amplo, permitindo interpretá-lo para além de um "filme de autor": era um filme de um "homem consciente do processo e consequente face ao processo. Por isso é que, mais do que qualquer outro, este filme consegue refletir e interpretar a realidade brasileira", e não simplesmente ser fiel ao realismo crítico. Assim, o cinema brasileiro saía, com o filme de Glauber, de um "tom menor realista para um cinema épico. Ele não cita Ford nem coisa nenhuma: cita o momento que Glauber vive neste país, cita a vida de Glauber e cita todo um processo do cinema brasileiro" (Hirszman apud Viany, 1999, p. 71), sendo corroborado nisso por Glauber, que afirmava, entre outras coisas, que o cinema brasileiro tinha tudo para ser um dos mais importantes do mundo. 
Vai ser mesmo, porque as condições culturais e políticas do Brasil e a feliz coincidência histórica com um nível de consciência - pode não ser nem talento - que o pessoal do Cinema Novo tem, constituem a chamada consciência histórica inevitável. Esse negócio que o Leon está dizendo é batata [...]. Eu acho que o filme aconteceu agora porque tive uma oportunidade de fazê-lo dentro de condições geográficas, históricas, econômicas et cetera e tal [...]. É o próprio complexo que está gerando as coisas; não é nenhuma felicidade individual de autor. [...] Não sou nenhum iluminado, não: sou consequência de um "negócio"; e o filme é consequência disso, é consequência do complexo cultural do Nordeste e do complexo de cultura cinematográfica que está iminente em toda esta geração, pronto para explodir em determinado momento, mais cedo em um, mais tarde em outro, devido às várias condições que entram em jogo. Cinema não é obra do acaso nem é obra de milagre (Glauber apud Viany, 1999, p. 72).

Creio que as passagens acima permitem vislumbrar, ainda que brevemente, a circulação de algumas ideias caras ao nacional-desenvolvimentismo, particularmente as perspectivas dualistas, o confronto com a realidade brasileira, o significado de alienação, compromisso e engajamento, em suma, parte do léxico com o qual cineastas e críticos de cinema compreenderam o contexto de mudança social que os cercava e que procuravam apresentar nas telas.

Contudo, tanto Deus e o diabo na Terra do Sol como sua recepção crítica acenavam também para outras perspectivas. Podemos situá-lo como um filme de transição, entre o que supomos aqui, provisoriamente, de uma abordagem estética derivada do nacional-desenvolvimentismo e que se propunha a "reapresentar" a realidade, e o projeto estético-político que viria pautar o Cinema Novo em meados de 1960. Deus e o diabo é exemplar da tensão entre a reprodução 
naturalista dos fatos e uma linguagem figurativa que atualizava, na própria montagem, uma reflexão sobre tais fatos. Na crítica contemporânea de Ismail Xavier (2007, p. 142), o filme teria cristalizado um projeto "estético-ideológico valorizador da representação folclórica, enquanto foco de resistência cultural e logos onde se engendra a identidade nacional, empenhado na transformação da sociedade e valorizando, nesse empenho, uma visão dialética da história”. Recusava-se a descartar a visão de mundo das classes dominadas, embora questionasse a face tradicionalista daquela representação, em nome da história, isto é, de um processo de transformações estruturais inserido no horizonte daquele momento. Assim, Deus e o diabo seria um filme-chave por incorporar em sua própria estrutura interna as contradições sociais e extrair disso sua força retórica e imagética. Nas palavras de Ismail Xavier (2007, p. 138):

O chamado à consciência deve se dar num estilo que dá continuidade à forma popular de resistência cultural consagrada pela tradição. Mas entre a poesia popular e a perspectiva do filme existe uma brecha. O veículo da representação é outro e há uma vertente progressista dentro do discurso que polemiza com a tradição e parte dos mitos para inseri-los num processo de transformação, denunciando seus limites, sua humanidade.

Com isso, o filme pôde representar um momento de grandes esperanças políticas no Brasil, ao configurar um herói progressista que, ao se libertar das "influências retrógradas e antirrepublicanas", acenava com as imagens marítimas tidas como a "principal matriz dos motivos utópicos hoje disponíveis no cinema brasileiro" (Nagib, 2006, pp. 25 e 39$)^{8}$.

${ }^{8}$ Lúcia Nagib alude aqui, apoiada também em Ismail Xavier, à metáfora que a 


\section{0 sonho em busca de sua expressão fílmica: "América nuestra" e uma nova linguagem latino-americana}

Ainda na década de 1950, simultaneamente ao debate em torno do "cinema verdade" e da recepção do neorrealismo que acontecia no Brasil, a formação comum (e bastante eclética) recebida por alguns jovens cineastas da Argentina e de Cuba, reunidos no Centro Sperimentale di Cinematografia de Roma, os impulsionaria, a partir dos anos 1960, a buscar um "nuevo cine latinoamericano". Compartilhando também o interesse pelo neorrealismo, pelo cinema épico de Eisenstein, pelo neossurrealismo de Buñuel e pela nouvelle vague francesa, cineastas como Fernando Birri, Julio García Espinosa e Tomás Gutiérrez Alea acrescentariam o conteúdo político-social que marcaria o empenho em busca dessa nova linguagem para um cinema latino-americano (Villaça, 2002, p. 490).

Da tríade de cineastas e intelectuais acima, Fernando Birri, ao retornar da Itália, fundaria em 1956, na Argentina, o Instituto de Cinematografia de Santa Fé, dentro da Universidad Nacional del Litoral. Considerada a primeira escola de cinema da América Latina, o Instituto foi responsável pela formação de diversos cineastas argentinos e latino-americanos, abrigando também os brasileiros Maurice Capovilla, Vladimir Herzog e influenciando o fotógrafo e documentarista Thomaz Farkas, os quais, como tantos outros, interessaram-se pela proposta metodológica e seleção temática inovadoras, bem como pelo caráter documental

sequência final do filme apresenta, do mar como imagem de redenção e esperança de transformação e utopia. O leitmotiv "o sertão vai virar mar e o mar vai virar sertão", foi inspirado em Antonio Conselheiro, e, pronunciado pelos personagens e anunciado pelo enredo cantado por Sérgio Ricardo, na canção em estilo de cordel, que estabelece o sentido do roteiro, aludia ao destino não traçado pelos personagens Corisco e Dada e o vaqueiro Manuel. Contudo, é um destino situado acima das possibilidades dos personagens, embora caracterizado no filme como a conclusão de que a história pertence ao homem, e não a Deus nem ao diabo. Ou seja, a história-destino caminhava através daquelas figuras, e não apesar delas. Cf. Xavier (2007) e Nagib (2006). 
e de inspiração neorrealista que aquele centro propunha (Lima, 2006, p. 172).

Já os cineastas Julio García Espinosa e Tomás Gutiérrez Alea teriam destacada participação no Instituto Cubano del Arte e Indústria Cinematográficos (ICAIC) a partir da década de 1960 e, ao lado de seu diretor, o militante comunista Alfredo Guevara, seriam igualmente influenciados por Glauber Rocha, particularmente após a divulgação de seu manifesto "Estética da Fome" durante a V Rassegna del Cinema Latino-Americano realizado em Gênova, em 1965 (Villaça, 2002, p. 495).

Desde 1960, Glauber Rocha começara a manter correspondências regulares com alguns daqueles cineastas e críticos, e, em particular, com o diretor do ICAIC, Alfredo Guevara. Ainda às voltas com a divulgação de Barravento, Glauber Rocha já anunciava a Guevara sua intenção em retratar e denunciar a realidade do subdesenvolvimento e, ao mesmo 132 tempo, instigar sua transformação, isto é:

[...] desenvolver um cinema verdadeiro e nacional, seguindo aquela linha política que foi inaugurada com Rio, 40 graus. Hoje os problemas estão mais acentuados e acreditamos que nosso filme seja a primeira grande denúncia já realizada no cinema do Brasil [...]. As fotografias que seguem podem dar uma ideia do ambiente, do dinamismo e das características particulares de Barravento, cujo significado é "transformação", "revolução". Fala alto pela necessidade das classes negras e exploradas levantarem um grito contra a exploração dos industriais (de Glauber Rocha para Alfredo Guevara, 27 dez. 1960, apud Rocha, 1997, p. 132).

Em resposta, Alfredo Guevara se manifestava interessado em "saber que por toda América Latina brota um nuevo movimiento cinematográfico, pleno de fuerza y sinceridad", atribuindo ainda a Barravento a oportunidade de abertura 
de um "período de verdadera amistad y colaboración, como lo queremos con los movimientos cinematográficos de verdadera calidad de toda América Latina, y aún del mundo entero" (de Alfredo Guevara para Glauber Rocha, 4 fev. 1961, apud Rocha, 1997, p. 137).

Iniciava-se assim uma amizade entre Alfredo Guevara e Glauber Rocha que duraria até a década seguinte, com repercussões não apenas nas trajetórias de ambos, como também nas dos grupos aos quais estavam respectivamente vinculados, passando também pelo reconhecimento que o cinema brasileiro recebia de cineastas cubanos desde antes da Revolução de 1959 (Villaça, 2002, p. 494).

Em diversas cartas trocadas entre Glauber e cineastas expoentes do Cinema Novo, notava-se um entusiasmo compartilhado pela América Latina, de tal sorte que, desde 1962, Glauber ambicionava produzir América nuestra, um "grande filme" que pudesse traduzir "o drama da América em luta”. Sua dimensão épica começava pela própria forma de realização, em coprodução com equipes específicas em Cuba, Argentina, Brasil e México (de Glauber para Alfredo Guevara, 21 nov. 1962, apud Rocha, 1997, p. 174). Contudo, somente em 1967 Glauber apresentaria a Alfredo Guevara a ideia geral de América nuestra.

É um filme muito ambicioso, onde quero mostrar o processo de destruição e libertação da América Latina, desde a destruição dos Incas pelos conquistadores, a influência da igreja, a criação dos latifúndios e da opressão, a chantagem da política civil e por fim as guerrilhas como caminho de liberação. Deve ser um filme épico e violento [...] Perdoe-me a pretensão, mas pretendo fazer uma estrutura épica no estilo de Outubro, com muita força poética e emoção revolucionária. Creio que um filme POLÍTICO deve ser também um ESTÍMULO CULTURAL E ARTÍSTICO. E para nós, latinos, que somos 
colonizados cultural e economicamente, o nosso cine deve ser revolucionário do ponto de vista político e poético, isto é, temos de apresentar IDEIAS NOVAS COM NOVA LINGUAGEM. América Nuestra não pretende ser um filme DIDÁTICO mas um COMÍCIO, UM FILME DE AGITAÇÃO, UM DISCURSO VIOLENTO e também uma prova de que, no terreno da cultura, o homem latino, liberado da opressão colonizadora, pode CRIAR (de Glauber Rocha para Alfredo Guevara, 1 jul. 1967, apud Rocha, 1997, p. 29293; DESTAQUES de Glauber Rocha).

Dedicando-o à memória de Che Guevara - morto em 9 de outubro de 1967 -, América nuestra deveria ser também "uma História Prática Ideológica Revolucionária da América Latina”, documentando os índios e a decadência imposta pela civilização, explicando os fenômenos das "revoluções de Bolívar, a contradição da revolução mexicana, o fenôme134 no do imperialismo e das ditaduras, a verdadeira revolução cubana e as contradições atuais para o desenvolvimento e vitórias das guerrilhas". Tão grande era a expectativa com a realização daquele filme que Glauber não hesitara em considerá-lo “'a última tentativa com o cinema'. Depois, creio, o caminho será o da luta aberta” (de Glauber para Alfredo Guevara, 3 nov. 1967, apud Rocha, 1997, p. 305).

América nuestra jamais foi produzido. Contudo, os argumentos utilizados para apresentá-lo, em diversas ocasiões e a vários interlocutores, sintetizam um conjunto de valores que sinalizam a ruptura estético-política com a perspectiva da "denúncia" social como forma de apresentar a realidade, como Glauber pensava no início da década de 1960. Se, em Deus e o diabo, a narrativa alegórica já indicava esse percurso, seria com Terra em transe, realizado em 1967 e refletindo a derrota do projeto nacionalista de esquerda e do populismo - e incorporando parte do roteiro desejado para América nuestra -, que Glauber pensaria o cinema para além de 
um projeto nacional, como uma cinematografia expressiva dos dramas da "América Latina”, do subdesenvolvimento e da "consciência possível" do colonizado. A trajetória desse projeto passa pelo manifesto "Estética da Fome", desdobra-se no distanciamento para com o realismo crítico e apresenta-se na trama, personagens e montagem de Terra em transe, avançando ainda pelo projeto estético-político do "tropicalismo". Eis, em suma, o roteiro de um cinema revolucionário, expressivo daquilo que Glauber e outros cineastas concebiam como consciência latino-americana.

A "fome latina" não é apenas um sintoma, mas o "nervo de sua própria sociedade", afirmava Glauber em "Estética da Fome", de 1965. Nossa originalidade seria, portanto, nossa "fome e nossa maior miséria é que esta forme, não sendo sentida, não é compreendida” (Rocha, 2004, p. 66; grifos meus). A compreensão da realidade - e sua superação - passaria antes pelos sentidos do que pela intelecção, traduzindo a tomada de consciência como um ato de "violência" que, antes de ser "primitiva”, seria "revolucionária”, ponto de partida para a compreensão, por parte do "colonizador", da existência do "colonizado" (Rocha, 2004, p. 66). Dessa forma, o Cinema Novo não seria uma "entidade privilegiada do Brasil", mas um "fenômeno dos povos colonizados", resultado da descoberta de uma experiência comum de exploração e subdesenvolvimento. Glauber rompia com o pressuposto estético-político norteado pelo nacional-desenvolvimentismo ao aderir à concepção terceiro-mundista, legitimadora a seu ver, de uma cinematografia "latino-americana”. Em "Teoria e prática do cinema latino-americano” (artigo escrito em 1967), Glauber é explícito quanto a esse ponto.

Na década de 50 se falava do cinema mexicano. No princípio da década de 60 se falava do cinema argentino, depois em cinema cubano, em seguida de cinema 
brasileiro. Agora se fala de cinema latino. Quando se fala de cinema latino, a significação ultrapassa o sentido puramente cinematográfico. A consciência latina começa se popularizar. A descoberta de que o Brasil, México, Argentina, Peru, Bolívia etc. fazem parte do mesmo bloco de exploração norte-americana e de que esta exploração é uma das causas mais profundas do subdesenvolvimento se concretizar a cada dia que passa e, o mais importante, se populariza. A noção de América Latina supera a noção de nacionalismos. Existe um problema comum: a miséria. Existe um objetivo comum: a libertação econômica, política e cultural de fazer um cinema latino. Um cinema empenhado, didático, épico, revolucionário. Um cinema sem fronteiras, de língua e problemas comuns (Rocha, 2004, p. 83).

Se Glauber já concebia o cinema como um "trabalho 136 científico, universitário - um trabalho de importância sociológica, antropológica e política" (de Glauber Rocha para Walter da Silveira, 19 abr. 1962, apud Rocha, 1997, p. 171), definindo também o labor cinematográfico como tarefa intelectual, tal concepção seria aprofundada ao imaginar, em textos como "A revolução é uma Eztetyka” (de 1967), o cineasta como um intelectual em ação, isto é, um "técnico, um economista, um publicista, um distribuidor, um exibidor, um crítico, um espectador e um polemista. O cineasta deve ser um homem de ação, física e intelectualmente preparado para a luta" (Rocha, 2004, p. 103). Entendendo o cinema como uma arma a serviço da revolução social, Glauber passaria a hostilizar também a linguagem discursiva e realista pela qual o cinema se pautara até então - incluindo suas próprias realizações anteriores a Terra em transe. Um cinema "revolucionário" não se comportaria numa "linguagem velha”, isto é, amparada pelo compromisso com o "realismo flaubertiano, com o teatro Gorki-Tchekov-Shaw, com 
a estética de Lukács. O cinema tem de entrar no território da linguagem como a América no território da revolução" (de Glauber Rocha para Jean-Claude Bernadet, 12 jun. 1967, apud Rocha, 1997, p. 282) ${ }^{9}$. Mais do que tudo, o cineasta, como de resto, o "intelectual latino-americano" não teria outro caminho válido senão integrar-se totalmente à "revolução, livre de qualquer compromisso com a estética e com a moral burguesa” (de Glauber para Alfredo Guevara, 3 nov. 1967, apud Rocha, 1997, p. 304).

Tanto pela forma narrativa como, em parte, pelo desenvolvimento temático e pela alusão a uma experiência histórica sem referências exclusivas ao contexto brasileiro, Terra em transe pode ser lido como o momento maior da problematização da ideia de "América Latina" no pensamento de cinema brasileiro na década de 1960. Se o dilema vivido pelo ambíguo personagem Paulo Martins expressava, por um lado, o desengano, o alijamento do poder e a derrota histórica do nacionalismo de esquerda diante do golpe militar de 1964 no Brasil, por outro lado projetava uma trama povoada de alegóricas representações das forças sociais e políticas do continente latino-americano: a elite tradicionalista, aristocrática, cristã e conservadora representada por Diaz - referência ao ditador mexicano Porfírio Diaz, bem como, genericamente, ao "conquistador ibérico" e à figura do tirano $^{10}$; a burguesia progressista, face moderna da classe

\footnotetext{
9 Tal postura, aliás, fora bastante criticada por Jean-Claude Bernadet. Em resposta à carta de Glauber, Bernadet via como idealismo e mesmo certa ingenuidade creditar ao cinema uma tarefa que ele não podia realizar: "ser um fato transformador da sociedade". Isto é, o cinema, como "veículo de formas e ideias" não poderia transformar "sem que a sociedade se transform[asse] estruturalmente; é a transformação da sociedade que transformará o cinema" (de Jean Claude-Bernadet para Glauber Rocha, 21 jul. 1967. In: Rocha, 1997, p. 290; grifos de J. C. Bernadet).

${ }^{10}$ Segundo Octávio Ianni (1988, p. 29), o "tirano" constitui-se num personagem particularmente emblemático na produção artística latino-americana: "ele está no romance, poesia, teatro, pintura e outras formas. Metido em incidentes, vivendo situações. Em vários romances, o tirano é o personagem principal, em torno do qual gravitam ministros, secretários, diplomatas, empresários, fazendeiros, intelectuais, duplos, sombras; ao mesmo tempo que aí gravitam a sociedade, a história, a
} 
dominante e que, na ausência de projeto político autônomo, oscila entre o apoio ao populismo e a manutenção da ordem autoritária, representada por Fuentes; o líder populista, de origem rural e com verniz urbano, oligarca dissidente que se alia ao progresso, representado por Vieira; a militante partidária de esquerda, disciplinada e dogmática, vivida por Sara; o herói arrogante e ambicioso representado por Paulo Martins, oscilante entre o engajamento político e o subjetivismo poético, o intelectual que, ao romper com Diaz e ajudar a construir Vieira como um novo líder, revela a veia autoritária ao lidar com o povo (Xavier, 1993, p. 55). O drama político vivido em Eldorado, "país interior atlântico", conduz à distopia, projeta o inferno àquela que seria a realização da utopia quinhentista da Idade do Ouro, o El Dorado dos conquistadores espanhóis.

Ao comentar o filme a alguns interlocutores, Glauber afirmara tê-lo concebido como uma "ruptura conscien138 te, parto a fórceps, aborto monstro”, cujo objetivo era ser "desastrosamente polêmico, em vários níveis do político ao estético” (de Glauber Rocha para Jean-Claude Bernadet, 12 jun. 1967, apud Rocha, 1997, p. 282). Ainda, que se tratava de uma "parábola sobre a crise ideológica e política da América Latina, onde os valores se entrechocam sem encontrar o caminho válido e consequente: a luta revolucionária" (de Glauber Rocha para Alfredo Guevara, s.d. 1967, apud Rocha, 1997, p. 274). A radicalidade da forma alegórica, superando a narrativa linear e organizadora do tempo-espaço fílmico, até então predominante no cinema, permitia a Glauber explorar ao máximo o "fluxo de consciência" de Paulo Martins, personificando o intelectual que revia, na agonia solitária da derrota, suas opções cambiantes entre direita e esquerda, populismo e autoritarismo, adesão

Nação [...]. O poder do tirano está em que ele absorve e sintetiza não só o governo, o regime e o Estado, mas também a sociedade, o povo e a Nação. Esta realiza-se e dissolve-se nele". 
ao nacionalismo de esquerda e à tradição conservadora (Napolitano, 2007, p. 605). Tratava-se da interpolação entre a "realidade externa" e o "fluxo febril do pensamento", ambos dilacerados; a montagem, por sua vez, expunha o fluxo subjetivo de Paulo Martins, o narrador em off do drama político, transcendendo todavia, sua própria subjetividade (Xavier, 1993, p. 39) ${ }^{11}$.

Entre 1967 e 1971, Glauber radicalizaria ainda mais sua crítica aos pressupostos do realismo crítico, a seu ver incompatíveis com uma linguagem "latino-americana". Na verdade, ao (re)valorizar a antropofagia expressa pelo modernista da Semana de 22, Oswald de Andrade, e ao endossar o movimento estético-político contemporâneo do "tropicalismo", Glauber buscava no "inconsciente coletivo" e nos elementos típicos da cultura popular uma linguagem efetivamente emancipadora da chamada "cultura colonial": a linguagem, compreendida como "expressão da consciência”, deveria incorporar o registro subjetivo ou inconsciente da experiência latino-americana, traduzindo o drama político em ideogramas, signos e mitos que levassem ao esclarecimento - algo que a intelecção e o discurso não conseguiriam. A legitimidade da mitologia estava patente, por exemplo, na experiência concreta "surrealista" dos povos latino-americanos, recuperada pelo tropicalismo.

E o surrealismo é coisa latina. Lautréamont era uruguaio e o primeiro surrealista foi Cervantes. Neruda fala de

\footnotetext{
${ }^{11}$ A forma narrativa de Terra em transe influenciaria, por sua vez, cineastas cubanos como Tomás Gutiérrez Alea e Julio García Espinosa: o primeiro lançaria, em 1968, Memorias del subdesarrollo, que se assemelha a Terra em Transe pela estrutura de colagem, pelas narrativas não lineares, pelo foco narrativo em personagens que vivenciam crises de identidade, pelas reflexões sobre a situação sociopolítica e mistura de diferentes estilos de cinema (Villaça, 2002, p. 498). Já a ideia de um cinema imperfeito como tradução da ruptura formal com a estética herdeira das "culturas colonizadoras" seria também apresentada por Julio García Espinosa em seu texto "Por um cine imperfecto", escrito em 1969.
} 
surrealismo concreto. É o discurso das relações entre fome e misticismo. O nosso não é o surrealismo do sonho, mas da realidade. Buñuel é um surrealista e seus filmes mexicanos são os primeiros filmes do tropicalismo e da antropofagia. A função histórica do surrealismo no mundo hispanoamericano oprimido foi aquela de ser instrumento para o pensamento em direção a uma liberação anárquica, a única possível. Hoje realizada dialeticamente, em sentido profundamente político, em direção ao esclarecimento e à agitação (Rocha, 2004, p. 153).

Se o racionalismo era opressor, porque trazia em seu bojo a cultura do colonizador, e os "sistemas culturais atuantes, de direita e de esquerda", estavam presos àquela "razão conservadora”, a única saída possível seria pela ruptura com os "racionalismos colonizadores", o que implicaria a recusa da própria estética "revolucionária” expressa em Terra em 140 transe, por exemplo: a revolução teria que se pautar pela "antirrazão", a única linguagem que comunicaria as "tensões e rebeliões do mais irracional de todos os fenômenos que é a pobreza" (Rocha, 2004, p. 250; grifos do autor). Em "Eztetyka do sonho", de 1971, Glauber encaminharia mais essa ruptura, na verdade, parte da obsessão em torno de uma linguagem fílmica legitimamente revolucionária, uma vez que "o irracionalismo libertador é a mais forte arma do revolucionário". A linguagem encontrada estaria nas "raízes índias e negras do povo latino-americano [...], única força desenvolvida deste continente", uma vez que "nossas classes médias e burguesias [seriam] caricaturas decadentes das sociedades colonizadoras" (Rocha, 2004, p. 251).

Curiosamente, o percurso em direção aos "mitos originais da minha raça” (Rocha, 2004), preocupação que contagiara parcelas expressivas dos intelectuais brasileiros, seria feito por Glauber com a descoberta da "América Latina". Residindo em Cuba em 1971, a convite de Alfredo Guevara 
e reconhecido por Fidel Castro, Glauber resolvera, ajudado pelo bolsista brasileiro Marcos Medeiros, produzir um documentário junto ao ICAIC, intitulado História do Brasil, inicialmente com sete horas de duração e montado a partir de colagens de trechos de vários filmes brasileiros pertencentes ao acervo daquele Instituto (Villaça, 2002, p. 502).

Ironicamente, aquela História do Brasil narrada a partir da linguagem obsessivamente procurada para dar vazão à experiência latino-americana, desagradara Alfredo Guevara, que retirou o nome do ICAIC dos créditos finais do filme - o qual só viria a ser finalizado em Roma, em 1974. O episódio azedaria também a relação de Glauber com Guevara e demais autoridades cubanas, repercutindo indiretamente para a dispersão e pulverização do próprio Nuevo Cine. O encontro entre o pensamento de cinema no Brasil e a "América Latina", contudo, renderia novos lances no futuro, embora não pautados pelo mesmo empenho e significado dos anos 1950 e 1960.

\section{Alexandro Dantas Trindade}

é professor de Ciência Política e Sociologia da UFPR.

\section{Bibliografia}

AUTRAN, A. 2002. "Alex Viany e Guido Aristarco: um caso das ideias fora do lugar”. Sinopse, v. IV, n. 8, abr.

AVELLAR, J. C. 1995. A ponte clandestina: Birri, Glauber, Solanas, García

Espinosa, Sanjinés, Alea - Teorias de cinema na América Latina. Rio de Janeiro/São Paulo: Ed. 34/Edusp.

BASTOS, E. R. 2006. As criaturas de Prometeu: Gilberto Freyre e a formação da sociedade brasileira. São Paulo: Global.

BETHEL, L. 2009. "O Brasil e a ideia de 'América Latina' em perspectiva história”. Estudos Históricos, Rio de Janeiro, v. 22, n. 44, pp. 289-321, jul.-dez. BOMFIM, M. 1905. A América Latina: Males de Origem. Rio de Janeiro/ Paris: H. Garnier.

BOTELHO, A. 2008. "Uma sociedade em movimento e sua intelligentsia: apresentação”. In: BOTELHO, A. et al. (orgs.). O moderno em questão: a década de 1950 no Brasil. Rio de Janeiro: Topbooks. 
BRUIT, H. H. 2000. "A invenção da América Latina”. In: V ENCONTRO DA ANPHLAC. Belo Horizonte. [Anais Eletrônicos.]

CARVALHO, J. M. 1991. "A utopia de Oliveira Viana”. Estudos Históricos, v. 4, n. 7, pp. 82-99.

. 1996. A construção da ordem: a elite política imperial; Teatro de sombras: a política imperial. Rio de Janeiro: Ed. UFRJ/Relume Dumará.

DEBS, S. 2006. "1953-1973. Na margem do Estado, o nascimento da crítica cinematográfica”. In: RIDENTI, M.; BASTOS, E. R.; ROLLAND, D. (orgs.). Intelectuais e Estado. Belo Horizonte: Ed. UFMG.

FABRIS, M. 1994. Nelson Pereira dos Santos: um olhar neo-realista? São Paulo: Edusp.

FARRET, R. L.; PINTO, S. R. 2011. "América Latina: da construção do nome à consolidação da ideia”. Topoi, v. 12, n. 23, pp. 30-42, jul.-dez. IANNI, O. 1988. "A questão nacional na América Latina”. Estudos Avançados, São Paulo, v. 2, n. 1, mar. . 2004. "O Brasil moderno". In: Pensamento social no Brasil. Bauru: Edusc.

LIMA, M. C. A. 2006. "Cinema e transformação social: o Instituto de Cinematografia de Santa Fé (1956-1962)”. História, São Paulo, v. 25, n. 2, pp. 162-78.

142 NAGIB, L. 2006. A utopia no cinema brasileiro. São Paulo: Cosac Naify.

NAPOLITANO, M. 2007. "Forjando a revolução, remodelando o mercado: arte engajada no Brasil (1956-1968)". In. FERREIRA, J.; AARÃO REIS, D. (orgs.). Nacionalismo e reformismo radical (1945-1964). Rio de Janeiro: Civilização Brasileira.

NOVAIS, F. A. 1995. Portugal e Brasil na crise do antigo sistema colonial (17771808). São Paulo: Hucitec.

ORTIZ, R. 2006. Cultura brasileira e identidade nacional. São Paulo:

Brasiliense.

PERES COSTA, W. 1996. A espada de Dâmocles: o exército, a Guerra do Paraguai e a crise do Império. São Paulo: Hucitec/Ed. Unicamp.

PRADO Jr., C. 1961. Evolução política do Brasil e outros estudos. São Paulo: Brasiliense.

RICUPERO, B. 2008. Sete lições sobre as interpretações do Brasil. São Paulo: Alameda Editorial.

RIDENTI, M. 2000. Em busca do povo brasileiro. Rio de Janeiro: Record. . 2008. "Brasilidade vermelha: artistas e intelectuais comunistas nos anos 1950". In: BOTELHO, A.; BASTOS, E. R.; VILLAS BÔAS, G. (orgs.). O moderno em questão: a década de 1950 no Brasil. Rio de Janeiro: Topbooks. 
2010. Brasilidade revolucionária: um século de cultura e política. São Paulo: Ed. Unesp.

ROCHA, G. 1997. Cartas ao mundo / Glauber Rocha. [Org. Ivana Bentes.]

São Paulo: Companhia das Letras.

2003. Revisão crítica do cinema brasileiro. São Paulo: Cosac Naify. 2004. Revolução do Cinema Novo: Glauber Rocha. São Paulo: Cosac

Naify.

2006. O século do cinema: Glauber Rocha. São Paulo: Cosac Naify.

SILVA DIAS, M. O. 1986. “A interiorização da metrópole (1808-1853)”. In:

MOTA, C. G. 1822 dimensões. São Paulo: Perspectiva.

TOLEDO, C. N. 1978. Iseb: fábrica de ideologias. São Paulo: Ática.

TRINDADE, A. D. 2010. “O ‘descobrimento' no pensamento

cinematográfico brasileiro: diálogos possíveis quanto à identidade

nacional". Lua Nova, n. 81, pp. 47-74.

2011. "Crítica em transe: a circulação do pensamento sociológico

no pensamento de cinema no Brasil”. In: XV CONGRESSO

BRASILEIRO DE SOCIOLOGIA, Curitiba.

VIANY, A. 1999. O processo do Cinema Novo. Rio de Janeiro: Aeroplano.

VILLAÇA, M. M. 2002. “'América nuestra' - Glauber Rocha e o cinema cubano”. Revista Brasileira de História, São Paulo, v. 22, n. 44, pp. 489510.

VILLAS BÔAS, G. 2006. Mudança provocada: passado e futuro no

pensamento sociológico brasileiro. Rio de Janeiro: Ed. FGV.

XAVIER, I. 1993. Alegorias do subdesenvolvimento: Cinema Novo,

Tropicalismo, Cinema Marginal. São Paulo: Brasiliense.

. 2006. "Prefácio". In: ROCHA, G. O século do cinema: Glauber Rocha.

São Paulo: Cosac Naify.

. 2007. Sertão mar: Glauber Rocha e a estética da fome. São Paulo:

Cosac Naify. 


\section{A EMERGÊNCIA DA IDEIA DE "AMÉRICA LATINA" NO PENSAMENTO CINEMATOGRÁFICO BRASILEIRO}

\section{ALEXANDRO DANTAS TRINDADE}

Resumo: Este texto tem como objetivo investigar a circulação do imaginário sobre a "América Latina", produzido em diversas instâncias de produção discursiva, entre representantes da crítica e do pensamento de cinema no Brasil, durante as décadas de 1950 e 1960. Momento crucial da produção reflexiva em torno dos dilemas das transformações sociais, econômicas e políticas pelas quais o país passava, o contexto assinalado foi palco da emergência de diversas expressões culturais, artísticas e intelectuais, através das quais se revelava a disputa em torno do sentido dos processos de mudança política em curso. O presente artigo tem por meta analisar o debate no qual críticos de cinema, intelectuais e cineastas se posicionaram quanto à busca de uma expressão política e estética que, enquanto identidade latino -americana, fosse capaz de dar sentido ao protagonismo político daquela geração.

Palavras-chave: Pensamento Cinematográfico; Representações sobre América Latina; Intelectuais; Cinema Novo, Glauber Rocha.

\section{THE EMERGENCE OF THE IDEA OF "LATIN AMERICA" AT THE THOUGHT OF BRAZILIAN CINEMA}

Abstract: This paper aims to investigate the circulation of imagery about "Latin America", produced in several instances of discursive production, between intellectual representatives of film criticism in Brazil during the 1950s and 1960s. Crucial moment of reflexive production around the dilemmas of social, economic, and policies for which the country was, the context was the scene for the emergence of cultural, artistic and intellectual expressions, through which was 
revealed the dispute over the meaning of the processes of political change underway. The goal of this work is to analyze the debate in which film critics, scholars and filmmakers positioned themselves as the search for political and aesthetics expression that while Latin American identity, was able to make sense of the political leadership of that generation.

Keywords: Film Criticism; Representations of Latin America in Brazil; Intellectuals; "Cinema Novo”; Glauber Rocha. 